\title{
A Survey on the Impact of the Menstrual Cycle on Movement Disorders Severity
}

\author{
Anna Castrioto, Sara Hulliger, Yu-Yan Poon, Anthony E. Lang, Elena Moro
}

\begin{abstract}
Background: A possible influence of estrogens on the dopaminergic system has been hypothesized and investigated by several studies, and fluctuations in motor symptoms related to the menstrual cycle have been reported in some movement disorders patients. We designed a survey to quantify how frequently female patients with various movement disorders are affected by this phenomenon and its impact on symptom severity. Methods: A questionnaire was sent to 104 women between 18- and 60-years-old diagnosed with movement disorders and regularly followed at our centre. Results: From a total of 65 subjects who completed the questionnaire, 54 women reported the onset of their movement disorders before menopause. Twenty of them (37\%) experienced changes in their movement disorders during the menstrual cycle. In particular, there was a significant worsening of symptom severity before $(p=0.0005)$ and during menses $(p=0.0004)$. Conclusions: The possible role of such changes should be taken into account when evaluating the efficacy of various therapeutic interventions in movement disorder patients.
\end{abstract}

RÉSUMÉ: Enquête sur l'impact du cycle menstruel sur la sévérité des troubles du mouvement. Contexte : Plusieurs études ont évalué l'hypothèse selon laquelle les oestrogènes auraient une influence sur le système dopaminergique. Des fluctuations des symptômes moteurs reliées au cycle menstruel ont été rapportées chez certaines patientes atteintes de troubles du mouvement. Nous avons procédé à une enquête pour quantifier la fréquence de ce phénomène chez des patientes atteintes de différents troubles du mouvement et son impact sur la sévérité des symptômes. Méthodes : Un questionnaire a été envoyé à 104 femmes âgées de 18 à 60 ans chez qui un diagnostic de trouble du mouvement avait été posé et qui avaient été suivies régulièrement dans notre centre. Résultats : Cinquante-quatre des 65 femmes qui ont complété le questionnaire ont rapporté que leur trouble du mouvement avait commencé avant la ménopause. Vingt d'entre elles (37\%) avaient noté des changements dans leur trouble du mouvement au cours de leur cycle menstruel, notamment une augmentation significative de la sévérité des symptômes avant $(p=0,0005)$ et pendant les menstruations $(\mathrm{p}=0,0004)$. Conclusions : Le rôle possible de ces fluctuations devrait être pris en considération dans l'évaluation de l'efficacité de différentes interventions thérapeutiques chez les patientes atteintes de troubles du mouvement.

Can. J. Neurol. Sci. 2010; 37: 478-481

Although there is evidence of an influence of estrogen on the dopaminergic system, ${ }^{1-2}$ little is known about the exact mechanisms of action of estrogens on basal ganglia circuitry and their influence on movement disorders.

Epidemiological studies have found some clinical genderrelated differences in patients with Parkinson's disease (PD), such as a slightly greater prevalence of PD in men, ${ }^{3}$ higher motor scores (i.e., more severe disease) in men using the Unified Parkinson Disease Rating Scale and greater prevalence of levodopa-induced dyskinesia in women. ${ }^{4}$ Some studies have assessed the possible benefit of hormone replacement therapy in post-menopausal women with PD. ${ }^{5-6}$ Moreover, estrogens have been demonstrated to be neuroprotective in both in vitro and in vivo studies. ${ }^{7-8}$ These findings suggest possible dopaminergic and neuroprotective effects of estrogens.
Possible correlations between the menstrual cycle and fluctuations of motor symptoms have been reported in PD, ${ }^{9-10}$ as well as in other movement disorders, such as dystonia. ${ }^{11}$ Many of our female patients with different types of movement disorders attending the Movement Disorders Clinic (MDC) at

From the Movement Disorders Centre (AC, YYP, AEL, EM), Toronto Western Hospital, University Health Network, Faculty of Medicine (SH), University of Toronto, Ontario, Canada; Clinica Neurologica (AC), Università degli Studi di Perugia, Ospedale S. Maria della Misericordia, Perugia, Italy.

Received November 27, 2009. Final Revisions Submitted February 17, 2010. Correspondence to: Elena Moro, Movement Disorders Centre, Toronto Western Hospital, 399 Bathurst St, McL7-402, Toronto, Ontario, M5T 2S8, Canada. 
the Toronto Western Hospital (TWH) have reported subjective worsening of their motor symptoms along with the premenstrual and menstrual period. Intrigued by this, we designed a survey aimed at: 1. quantifying the proportion female patients affected by this phenomenon, 2. identifying to what extent fluctuations in motor symptoms were related to the menstrual cycle, and 3. assessing the overall subjective impression of changes in symptom severity with reproductive life events.

\section{METHODS}

\section{Patients}

From the pool of patients attending the TWH MDC, subjects were selected according to the following criteria of inclusion: a) female gender; b) age between 18 and 60 years, c) diagnosis of PD, dystonia, essential tremor or other movement disorders (myoclonus, tics, etc.), d) provided written permission to be contacted about possible involvement in clinical studies (required by our institution).

\section{Study design}

A letter outlining the study rationale and goals along with the written study consent form and a questionnaire were sent to each participant by mail.

The questionnaire encompassed questions about menstrual and reproductive life events histories, medication usage (including information about use of oral contraceptives or hormone replacement therapy), and premenstrual syndrome (using a modified Penn 17-item Daily Symptom Report ${ }^{12}$ ). Patients were asked their overall impression of change in severity of movement disorder symptoms with their menstrual cycle, choosing between three possible answers: no change, change or unsure. Patients were asked to score the severity of their motor symptoms from 0 to 10 (0: no symptoms; 10: the worst possible) during three phases of the menstrual cycle (the week before their periods, during their periods, one to two weeks after their periods) and to specify which of their neurologic symptoms changed. Further questions included possible changes in the effects of medications for the movement disorders during the menstrual cycle and subsequent changes in medical therapy related to their periods. Patients were also asked whether they were in menopause and had experienced any change in the movement disorders severity with menopause (no change, improvement after menopause, worsening after menopause, unsure) and with hormone replacement therapy. Other questions concerned pregnancy, such as possible changes during or after pregnancy (no change, improvement during/after pregnancy, worsening during/after pregnancy, unsure), and oral contraceptive use (never used, past user, current user) and related movement disorders change (no change, improvement, worse, unsure).

The study was approved by the University Health Network Research Ethics Board and all participants gave their written informed consent.

\section{Statistical analysis}

The primary outcome measures were to determine how many of the surveyed women experienced changes in the severity of their movement disorder during the different phases of the menstrual cycle and to define the characteristics, symptomatology and nature of these changes. Patients with onset of their movement disorder after menopause were not included in the analysis.

Secondary outcomes were to identify differences in demographics between patients with and without menstrual cycle-related changes in movement disorders and to detect subjective changes of movement disorder severity along with pregnancy and menopause.

A mixed model repeated measures analysis was used to determine whether severity ratings differed significantly across the three study phases. T-tests were performed to compare characteristics of patients with and without movement disorders fluctuations during the menstrual cycle.

\section{Results}

From the pool of 2,566 female patients attending the TWH MDC, only 104 patients met the inclusion criteria. Of these 104 subjects, $65(62.5 \%)$ returned the completed survey. Thirty-eight patients $(58.5 \%)$ were still having menstrual cycles, whereas 27 (41.5\%, 12 with dystonia, 9 with PD, 3 with hemifacial spasm, 2

Table 1: Main clinical characteristics of the patients. Data are presented as mean \pm SD

\begin{tabular}{|c|c|c|c|c|c|c|c|}
\hline & PD & DYSTONIA & HFS & ET & WD & $\mathrm{P}$ & TOTAL \\
\hline Number of patients & 17 & 26 & 4 & 4 & 2 & 1 & 54 \\
\hline Age, years (range) & $\begin{array}{c}50.5 \pm 6.6 \\
(40-60)\end{array}$ & $\begin{array}{l}47.5 \pm 7.7 \\
(20-56)\end{array}$ & $\begin{array}{c}45.3 \pm 9.2 \\
(35-53)\end{array}$ & $\begin{array}{c}31.5 \pm 10.8 \\
(22-47)\end{array}$ & $\begin{array}{c}43.0 \pm 14.1 \\
(33-53)\end{array}$ & 50 & $\begin{array}{c}47.0 \pm 8.9 \\
(20-60)\end{array}$ \\
\hline Age at disease onset, years (range) & $\begin{array}{c}40.5 \pm 7.9 \\
(30-53) \\
\end{array}$ & $\begin{array}{c}33.0 \pm 12.2 \\
(8-51)\end{array}$ & $\begin{array}{r}35.5 \pm 9.7 \\
(25-48) \\
\end{array}$ & $\begin{array}{c}14.8 \pm 2.0 \\
(13-17)\end{array}$ & $\begin{array}{c}25.0 \pm 25.5 \\
(7-43)\end{array}$ & 43 & $\begin{array}{c}34.4 \pm 12.4 \\
(7-53)\end{array}$ \\
\hline Disease duration, years (range) & $\begin{array}{c}10.5 \pm 4.5 \\
(3-18)\end{array}$ & $\begin{array}{c}15.1 \pm 12.1 \\
(1-47)\end{array}$ & $\begin{array}{c}10.7 \pm 5.5 \\
(5-16)\end{array}$ & $\begin{array}{l}19.8 \pm 11.1 \\
\quad(12-32)\end{array}$ & $\begin{array}{l}18.0 \pm 11.3 \\
(7-26)\end{array}$ & 7 & $\begin{array}{c}13.4 \pm 9.8 \\
(1-47)\end{array}$ \\
\hline $\begin{array}{l}\text { Number of patients with cycle-related } \\
\text { movement disorders changes }\end{array}$ & 11 & 7 & / & 2 & / & / & 20 \\
\hline
\end{tabular}

PD, Parkinson's disease; HFS, Hemifacial spasm; ET, essential tremor; WD, Wilson's disease; P, parkinsonism. 
with parkinsonism and 1 with essential tremor) were in menopause. In 11 of those patients ( 3 affected with dystonia, 2 with hemifacial spasm, 4 with PD, 1 with multiple system atrophy and 1 with essential tremor), the onset of movement disorder started after menopause and therefore these patients were excluded from the analysis. The main characteristics of the patients included in the analysis are summarized in Table 1.

Twenty patients $(37 \%)$ reported changes during menstrual cycle, 18 patients $(33.3 \%)$ no changes, $15(27.7 \%)$ were unsure and $1(1.9 \%)$ did not reply. Among the 54 subjects, $64.7 \%$ of PD patients and $26.9 \%$ of dystonia patients reported cycle-related movement disorders changes (Table 1).

All but one patient experiencing changes reported worsening related to menses; 9 patients reported symptom worsening during menses, 8 patients during the week before menses and 2 patients in both the week before and during menses. One patient (affected with dystonia) reported an improvement during menses.

The results of repeated measures analysis are reported in Table 2. Severity ratings changed significantly over the three phases of the menstrual cycle (with higher scores indicating greater severity of symptoms). Bonferroni-adjusted pairwise comparisons determined that scores were significantly lower after menses than the week before $(p=0.0005)$ and during menses $(p=0.0004)$. No significant difference was detected in scores between the week before and during menses.

Among PD women, off-medication dystonia was the commonest symptom worsening (eight patients, 72.7\%), followed by walking and sleep problems (7 patients each, $63.6 \%)$, balance and clumsiness (6 patients, $54.5 \%)$, tremor (5 patients, $45.5 \%)$, dyskinesia, speech, twitching, tingling and memory (3 patients, $27.3 \%$ ).

Dystonic patients mainly complained about dystonia worsening (6 patients, 85.7\%), secondly about worsening of tremor, twitching, walking (5 patients, $71.4 \%$ ), stiffness, balance, clumsiness (4 patients, 57.1\%), sleep and speech (3 patients, $42.9 \%$ ).

Patients with essential tremor reported worsening of the tremor.

Twelve patients reported that their current medications were less effective during the worsening of their symptoms, but only one patient with PD reported to need an extra dose of medications for her symptoms during her period (levodopa/ carbidopa $100 / 25 \mathrm{mg}$ /day). However, no other changes in pharmacological treatment were made during patients' menstrual cycles.
There was no association between the presence of fluctuations of movement disorders and age at disease onset or disease duration.

Fifty-five patients reported features consistent with premenstrual syndrome. In particular, all 20 patients with symptom fluctuations during the menstrual cycle suffered from premenstrual syndrome.

Forty-four patients $(67.7 \%)$ were past users and $6(9.2 \%)$ current users of oral contraceptives; two of these patients had experienced an improvement of symptoms in response to this intervention.

Only 6 out of the 41 patients who had been pregnant while they had their movement disorder reported changes in symptoms severity during pregnancy, 3 patients (one affected with hemifacial spasm, one with PD and one with dystonia) reporting an improvement, whereas the other 3 patients (one affected with PD and two with dystonia) reporting a worsening.

Of the 16 menopausal patients with movement disorder onset before menopause age, five subjects (31.3\%; four with dystonia and one with PD) reported a worsening of motor symptoms after menopause, two subjects (12.5\%, with dystonia) a probable worsening of symptoms, whereas only one subject $(6.2 \%$, with dystonia) reported an improvement.

Among the 54 patients, there were five dystonic patients with bilateral globus pallidus internus deep brain stimulation (DBS) (three in menopause) and three PD patients with bilateral subthalamic nucleus DBS (all in childbearing age, one treated also with unilateral globus pallidus internus DBS for off dystonia). In this surgical group 3 dystonia and 3 PD patients claimed to have symptom fluctuations with worsening of motor symptoms during the menstrual cycle despite ongoing DBS therapy.

\section{DISCUSSION}

The impact of estrogens and the menstrual cycle on movement disorders patients is an interesting and still poorly understood field. Previous studies have tried to investigate the relationship between motor fluctuations and menstrual cycle in women with PD, but have been limited by the small number of women involved. ${ }^{9-10}$ Other questionnaires have focused more on differences in the reproductive life events between healthy subjects and PD patients. ${ }^{13}$

The main finding of our study is that almost $40 \%$ of the women experience changes in their movement disorder symptoms during the menstrual cycle, mainly a worsening of the

Table 2: Mixed model repeated measures $(\mathrm{MMRM})$ results. Data are presented as mean $\pm \mathrm{SD}$

\begin{tabular}{c|c|c|c|c|c}
\hline \multirow{2}{*}{ Phase } & Week before menses & During menses & After menses & P value & F \\
\hline Severity rating & $5.50 \pm 2.89$ & $5.53 \pm 2.03$ & $3.10 \pm 2.34$ & 0.0001 \\
\hline
\end{tabular}

F, F distribution; df, degrees of freedom 
motor symptoms during the premenstrual and menstrual phases. This figure was strongly influenced by the larger number of patients with PD in our survey and the strong influence of the menstrual cycle on their motor symptoms; over $60 \%$ of these patients experienced changes with their periods. In these patients, off-medication dystonia was the feature reported to worsen the most.

Interestingly, patients treated with DBS surgery also reported fluctuations of motor symptoms during their menstrual cycle. The mechanism of action of DBS is still partly unknown, but recent evidence supports DBS influence on oscillatory activity of the basal ganglia. ${ }^{14}$ In these DBS patients with cycle-related impairment we can hypothesize that estrogen or other menstrualrelated factors overcome the beneficial effects of DBS probably modifying the oscillatory neuronal activity.

Several studies have tried to clarify a possible relationship between symptom fluctuations and reproductive events, hypothesizing that the worsening of neurological symptoms experienced during the premenstrual and menstrual phase were related to the nadir of serum estrogen and progesterone levels. However, the results achieved so far are still unclear. ${ }^{10}$ Moreover, the clinical manifestation of movement disorders is greatly influenced by stress and emotional changes. Almost all surveyed patients reported premenstrual syndrome features. Although this could account for the change in symptom severity reported and might support the hypothesis that motor worsening is not related to a direct effect of estrogen on the basal ganglia, it is unclear why only some patients experience this change and others not.

The major limitations of our study are related to the small number of patients surveyed and its retrospective nature. In particular, 27 of the surveyed women were in their menopause age and their accuracy in recalling movement disorders changes during menses could be inexact. The lower frequency of change in movement disorders symptoms reported by this group compared to those still having menses supports this possibility. Concerning the possible influence of menopause and pregnancy on movement disorders, our sample was too small to draw any definitive conclusions.

Nonetheless, the major purpose of this study was to estimate the relevance of these subjective phenomena among women attending a MDC and their impact on disease severity. Movement disorders specialists should take into account the possible influence of life reproductive events on movement disorders expression in their clinical practice, especially when assessing the efficacy of various therapeutic interventions in women with movement disorders.

\section{CONCLUSIONS}

Our findings, although retrospective and subjective, demand that more studies are needed to help clarify the role of sex hormones on movement disorders manifestations.

\section{ACKNOWLEDGEMENTS}

The authors thank Dr. T. Arenovich for the assistance in statistical analysis. The authors also thank Dr. J. Miyasaki, Dr. R. Chen, Dr. S. Fox, Dr. A. Strafella and Dr. C. Marras for sharing patients' data.

\section{REFERENCES}

1. Van Hartesveldt C, Joyce JN. Effects of estrogen on the basal ganglia. Neurosci Biobehav Rev. 1986;10:1-14.

2. Kompoliti K. Estrogen and movement disorders. Clin Neuropharmacol. 1999;22:318-26.

3. De Lau LM, Breteler MM. Epidemiology of Parkinson's disease. Lancet Neurol. 2006;5:525-35.

4. Lyons KE, Hubble JP, Troster AI, Pahwa R, Koller WC. Gender differences in Parkinson's disease. Clin Neuropharmacol. 1998; 21:118-21.

5. Blanchet PJ, Fang J, Hyland K, Arnold LA, Mouradian MM, Chase TN. Short-term effects of high dose 17beta-estradiol in postmenopausal PD patients: a crossover study. Neurology. 1999:53:91-5.

6. Tsang KL, Ho SL, Lo SK. Estrogen improves motor disability in parkinsonian postmenopausal women with motor fluctuations. Neurology. 2000;54:2292-8.

7. Leranth C, Roth RH, Elsewoth JD, Naftolin F, Horvath TL, Redmond DE Jr. Estrogen is essential for maintaining nigrostriatal dopamine neurons in primates: implications for Parkinson's disease and memory. J Neurosci. 2000;20:8604-9.

8. Sawada H, Ibi M, Kihara T, Honda K, Nakamizo T, Kanki R, et al. Estradiol protects dopaminergic neurons in a MPP+ Parkinson's disease model. Neuropharmacology. 2002;42:1056-64.

9. Quinn NP, Marsden CD. Menstrual-related fluctuations in Parkinson's disease. Mov Disord. 1986;1:85-7.

10. Kompoliti K, Comella CL, Jaglin JA, Leurgans S, Raman R, Goetz CG. Menstrual-related changes in motoric function in women with Parkinson's disease. Neurology. 2000;55:1572-5.

11. Gwinn-Hardy KA, Adler CH, Weaver AL, Fish NM, Newman SJ. Effect of hormone variations and other factors on symptom severity in women with dystonia. Mayo Clin Proc. 2000;75: 235-40.

12. Coffee AL, Kuehl TJ, Sulak PJ. Comparison of scales for evaluating premenstrual symptoms in women using oral contraceptives. Pharmacotherapy. 2008;28:576-83.

13. Ragonese P, D'Amelio M, Salemi G, Aridon P, Gammino M, Epifanio A, et al. Risk of Parkinson disease in women: effect of reproductive characteristics. Neurology. 2004;62:2010-14.

14. Devos D, Labyt E, Derambure P, Bourriez JL, Cassim F, Reyns N, et al. Subthalamic nucleus stimulation modulates motor cortex oscillatory activity in Parkinson's disease. Brain. 2004;127: 408-19. 